\title{
Impact of leg movement on skin-adductor canal distance: a potential cause for catheter tip displacement?
}

\author{
Marcus Tholin, MD (1) · Jason Wilson, MD, FRCPC $\cdot$ Steven Lee, MD, FRCPC • \\ Raymond Tang, MD, FRCPC · Andrew Sawka, MD, FRCPC $\cdot$ Himat Vaghadia, MBBS, FRCPC
}

Received: 5 March 2019/Revised: 31 January 2020/ Accepted: 13 February 2020/Published online: 8 May 2020

(C) Canadian Anesthesiologists' Society 2020

\begin{abstract}
Purpose Catheter-based adductor canal blocks are an effective pain management strategy for total knee arthroplasty. Nevertheless, catheter-based techniques may fail if the tip migrates because of leg movement. This observational study used ultrasound to measure the distance from the skin to the adductor canal (SAC). We tested the hypothesis that leg movements mimicking those occurring during postoperative physiotherapy change the SAC distance.

Methods Following total knee arthroplasty under spinal anesthesia, the SAC distance was measured using ultrasound in 40 patients. The leg was passively moved into five standardized positions: neutral, neutral position with manual lateral displacement of the skin, $30^{\circ}$ external rotation, straight leg raised to $30^{\circ}$, and knee and hip flexed to $90^{\circ}$.

Results The mean (standard deviation) SAC distance change from the neutral position was $+1.0(0.6) \mathrm{cm}$ with manual displacement, $+0.3(0.4) \mathrm{cm}$ with external rotation, $+0.4(0.4) \mathrm{cm}$ with straight leg raise, and $+0.6(0.5) \mathrm{cm}$ with leg flexion $(P<0.001$ for all positions $)$. SAC distance changes did not correlate with height, body mass index, or leg circumference.
\end{abstract}

\footnotetext{
M. Tholin, MD ( $\square)$

Department of Anesthesia and Perioperative Care, Vancouver General Hospital, Vancouver, BC, Canada

e-mail: marcus.tholin@vch.ca

Department of Anesthesia and Perioperative Care, Vancouver General Hospital, Jim Pattison Pavilion, 899 West 12th Avenue, 2nd floor, room 2449, Vancouver, BC V5Z 1M9, Canada

J. Wilson, MD, FRCPC $\cdot$ S. Lee, MD, FRCPC $\cdot$ R. Tang, MD, FRCPC $\cdot$ A. Sawka, MD, FRCPC $\cdot$ H. Vaghadia, MBBS, FRCPC

Department of Anesthesia and Perioperative Care, Vancouver General Hospital, Vancouver, BC, Canada
}

Conclusion Passive leg movements in five standardized positions increase the SAC distance. We speculate that the altered SAC distance associated with passive leg movement may contribute to catheter tip dislodgement and adductor canal block failure.

Trial registration $w w w . c l i n i c a l t r i a l s . g o v$, NCT03562559; registered 19 June, 2018.

\section{Résumé}

Objectif Les blocs du canal des adducteurs utilisant un cathéter constituent une stratégie efficace du contrôle de la douleur pour l'arthroplastie totale de genou. Néanmoins, les techniques reposant sur des cathéters peuvent échouer si leur extrémité migre du fait d'un mouvement de la jambe. Cette étude observationnelle a utilisé l'échographie pour mesurer la distance séparant la peau du canal des adducteurs (P-CA). Nous avons testé l'hypothèse que des mouvements de la jambe imitant ceux qui surviennent au cours de la physiothérapie postopératoire modifient la distance P-CA.

Méthodes Après une arthroplastie totale de genou sous rachianesthésie, la distance P-CA a été mesurée par échographie chez 40 patients. La jambe a été mobilisée passivement dans cinq positions standardisées : position neutre, position neutre avec déplacement latéral manuel de la peau, rotation latérale de $30^{\circ}$, jambe tendue soulevée à $30^{\circ}$ et, enfin, genou et hanche fléchis à $90^{\circ}$.

Résultats La modification de la distance P-CA moyenne (écart-type) à partir de la position neutre a été $+1,0(0,6) \mathrm{cm}$ avec le déplacement manuel, $+0,3(0,4) \mathrm{cm}$ avec la rotation latérale, $+0,4(0,4) \mathrm{cm}$ avec la jambe tendue soulevée et $+0,6(0,5) \mathrm{cm}$ avec la jambe fléchie $(P<0,001$ pour toutes les positions). Les modifications de la distance P-CA n'étaient pas corrélées à la taille, l'indice de masse corporelle ou la circonférence de la jambe du patient.

Conclusion Les mouvements passifs de la jambe dans cinq positions standardisées augmentent la distance P-CA. Nous 
pensons que la modification de la distance P-CA associée à un mouvement passif de la jambe peut contribuer au déplacement de l'extrémité du cathéter et à l'échec du bloc du canal des adducteurs.

Enregistrement de l'essai clinique $w w w$.clinicaltrials.gov, NCT 03562559; Enregistré le 19 juin 2018.

Total knee arthroplasty (TKA) is increasingly common in North America because of growing obesity rates and an aging population. ${ }^{1}$ Effective pain control using a multimodal approach decreases narcotic use, enhances patient satisfaction, and speeds up recovery. ${ }^{2}$ Regional anesthetic techniques such as the adductor canal block (ACB) have become a major component of multimodal pain management during the postoperative period. ${ }^{3-5}$

Adductor canal block consisting of a single injection or continuous infusion via an indwelling catheter is currently utilized, with the latter technique conferring the theoretical benefit of prolonged analgesia. ${ }^{6}$ The efficacy of catheter analgesia is predicated primarily on its placement and maintenance. Despite growing expertise with regional anesthesia and ultrasound-guided techniques, catheter tip displacement in other types of peripheral nerve blocks (e.g., interscalene, supraclavicular, infraclavicular, and femoral) has been reported to be as high as $26 \% .^{7-9}$ Catheter tip migration may partially explain the unexpected recent findings that ACB catheters do not reduce opioid consumption $^{10}$ and pain scores ${ }^{11}$ compared with single injections.

This observational study investigates anatomical and mechanical factors that may contribute to catheter failure. We examined whether the SAC distance changes when the leg is moved into various standardized positions. It is hypothesized that the SAC distance changes with leg position, and we speculate that repeated leg movements could gradually cause catheter tip migration.

\section{Methods}

With clinical research ethics approval from the University of British Columbia (H17-02633) and registration at clinicaltrials.gov (NCT03562559), informed written consent was obtained from 40 patients. This sample size of convenience was chosen arbitrarily as no previous data exist to allow for a power calculation. Patients were recruited from the Preoperative Clinic of the University of British Columbia Hospital from 1 March 2018 to 30 May 2018. Inclusion criteria were adult patients $(>18 \mathrm{yr}$ ) undergoing elective TKA under spinal anesthesia. Rather than using healthy volunteers, we studied TKA patients just after their surgical procedure. Results were derived from patients requiring an ACB and whose characteristics (e.g., age, height, weight and body mass index [BMI]) were representative of TKA patients elsewhere. Furthermore, ultrasound images and measured distances were more clinically relevant considering potential distortions of anatomy following surgery. Patients who received a general anesthetic were excluded from participation because we were concerned that the standardized leg manipulations used during the postoperative period to assess changes in SAC distance may cause discomfort.

For all participants, basic demographic data were obtained as well as the leg circumference at the level where the ACB was to be performed. Postoperatively, while still under spinal anesthesia, measurements were made on the patient's operated leg from the skin (ACB needle insertion site) to the adductor canal using a HLF50X 15-6 MHz transducer connected to a SonoSite SII ultrasound machine (Fujifilm, Toronto, ON, Canada). A single measurement at each leg position was recorded. The adductor canal was identified with the transducer in the transverse plane placed on the patient's thigh and the transducer's footprint was marked on the skin. The ultrasound transducer was always kept in the pre-marked footprint and oriented perpendicular to the thigh to help ensure consistency of measurements. This is where ACBs are performed at our institution, with the superficial femoral artery (SFA) abutting the inferior side of the vasoadductor membrane near the trough of the sartorious muscle. In accordance with the definition of the adductor canal by Wong et al., ${ }^{12}$ all measurements were made distal to the proximal border of the adductor canal where the medial border of the sartorius muscle intersects the medial border of the adductor longus muscle. The SFA in the adductor canal was used as a reference point for measurement. The distance from the skin to the most upper lateral corner of the SFA where it abuts the vasoadductor membrane was measured in the following five positions: 1) neutral, 2) neutral position with manual lateral displacement of the skin, 3) $30^{\circ}$ external rotation, 4) straight leg raised to $30^{\circ}$, and 5) knee and hip flexed to $90^{\circ}$ (Fig. 1). Position 2 simulates the thigh rolling with the back of the leg against the bed as the patient changes position, such as when turning or trying to sit up. Positions 3,4 , and 5 simulate movements commonly encountered during physiotherapy. With each position, the ultrasound image was saved and a measurement from the upper lateral corner of the image (skin) to the SFA was recorded (Fig. 2). The same operator (M.T.) performed all scans and measurements, while an assistant facilitated the various passive leg movements. All patients received a single-shot ACB with $20 \mathrm{~mL} \quad 0.5 \%$ ropivacaine (following 
Fig. 1 Standardized leg positions. a) neutral; b) manual displacement; c) external rotation; d) $30^{\circ}$ leg raise; e) $90^{\circ}$ knee flexion. (a)

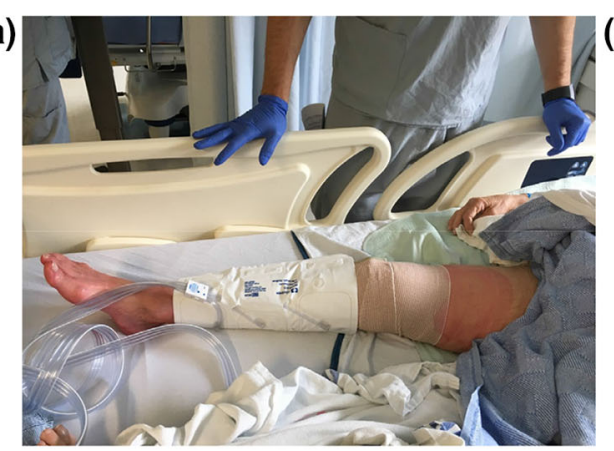

(c)

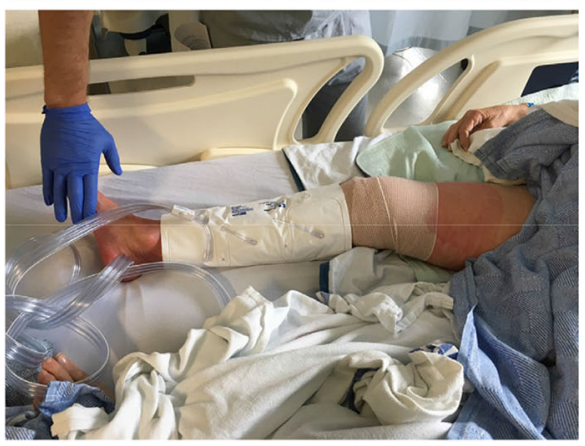

(e)

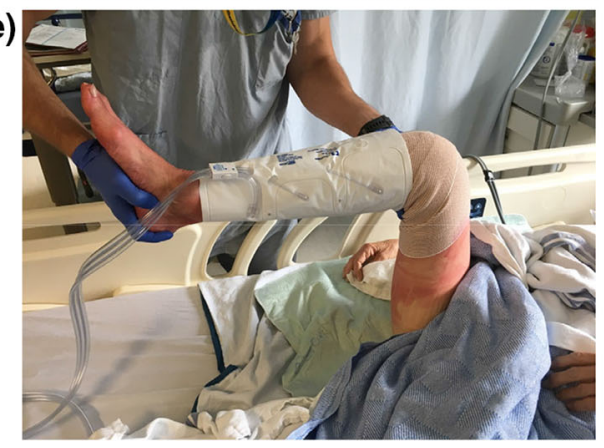

(b)

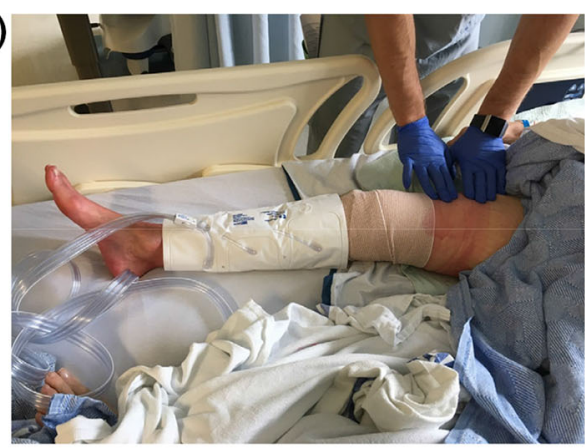

(d)

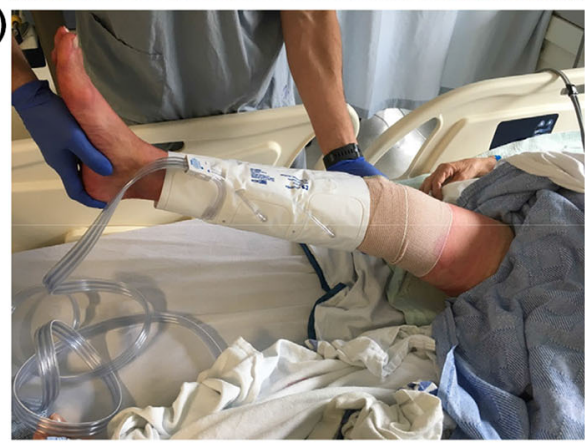

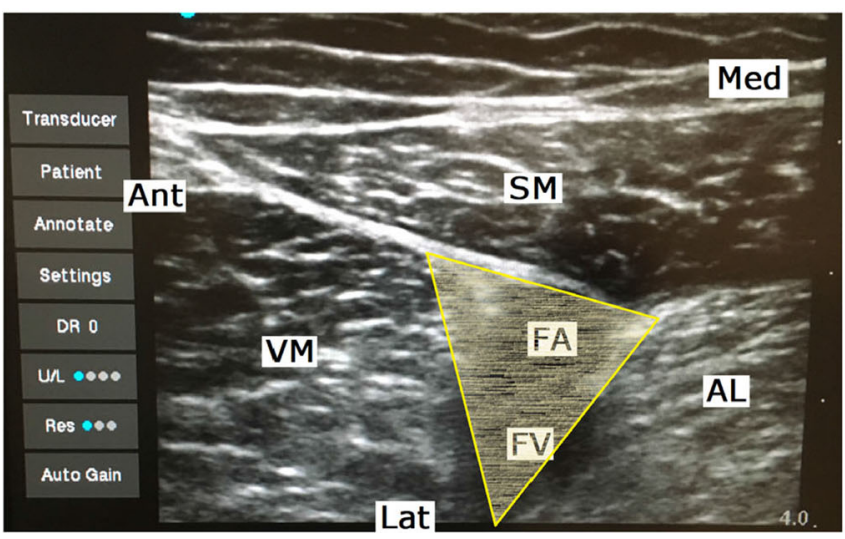

Fig. 2 Ultrasound image of adductor canal. Ultrasound transducer placed on medial aspect of thigh (over site of ACB needle insertion; see text for details). Red line shows distance measured from anterolateral edge of ultrasound transducer (skin) to the surface of the femoral artery (placement of needle or catheter tip for local

measurements) as part of our standardized pain management protocol. No post-block measurements were

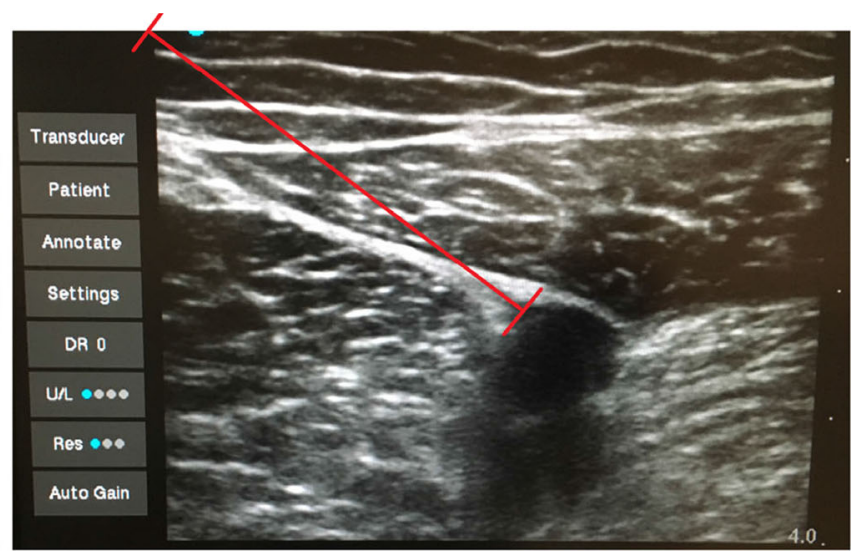

anesthetic injection). $\mathrm{ACB}=$ adductor canal block; $\mathrm{AL}=$ adductor longus; $\mathrm{Ant}=$ anterior; $\mathrm{FA}=$ femoral artery; $\mathrm{FV}=$ femoral vein; $\mathrm{Lat}=$ lateral, $\mathrm{Med}=$ medial $; \mathrm{SM}=$ sartorius muscle $; \mathrm{VM}=$ vastus medialus . Yellow triangle outlines the approximate area of adductor canal.

made as the anatomy is considerably distorted following injection of local anesthetic. 
The primary outcome of interest was the SAC distance change associated with the various leg positions. Secondary outcomes included the relationship of SAC distance changes with height, BMI, and leg circumference. All SAC measurements were tested for normality using the Kolmogorov-Smirnoff test with Lilliefors correction. Normally distributed measurements were analyzed using the paired-sample $t$ test; otherwise the Wilcoxon signedrank test was used. Mean and standard deviation (SD) were also calculated. Data were analyzed using software NCSS 11.0.12 (Kaysville, UT, USA). The trend of relative distance change in each position was plotted against the patient's height, BMI, and leg circumference. A line of best fit and r-squared value was calculated using Microsoft Excel 365 (version 1908).

Table 1 Demographic data

\begin{tabular}{ll}
\hline Characteristic & Value \\
\hline Male, $n /$ total (\%) & $23 / 40(57)$ \\
Age (yr), mean (SD) & $67.6(9.2)$ \\
Leg circumference (cm), mean (SD) & $55(5.7)$ \\
Height (cm), mean (SD) & $167(11.7)$ \\
Weight (kg), mean (SD) & $87(19.2)$ \\
BMI, median [IQR] & $30.3[27.9-33.5]$ \\
\hline
\end{tabular}

$\overline{\mathrm{BMI}}=$ body mass index; $\mathrm{IQR}=$ interquartile range; $\mathrm{SD}=$ standard deviation.

\section{Results}

Demographic characteristics for 40 subjects (23 male, 17 female) are shown in Table 1. Data for primary and secondary outcomes are presented in Tables 2 and 3. All SAC measurements other than straight leg raise were normally distributed. The mean (SD) SAC distance in the neutral position was $5.1(0.8) \mathrm{cm}$, manual tissue displacement was $6.1(0.8) \mathrm{cm}$, external rotation was 5.4 $(0.8) \mathrm{cm}$, straight leg at $30^{\circ}$ was $5.5(0.7) \mathrm{cm}$, and flexed position was $5.7(0.9) \mathrm{cm}$. Using the neutral position as baseline, the mean (SD) relative SAC distance change was $+1.0(0.6) \mathrm{cm}$ with manual displacement, $+0.3(0.4) \mathrm{cm}$ with external rotation, $+0.4(0.4) \mathrm{cm}$ with straight leg raise, and $+0.6(0.5) \mathrm{cm}$ with flexed leg. The mean relative distance changes were all different from the baseline measurement $(P<0.001)$. There was no difference regarding sex on the SAC distance measurements with each leg position, or changes in SAC distance compared with baseline (Table 2). There was no correlation between the SAC distance changes and leg circumference, height, or BMI (Table 3).

\section{Discussion}

Adductor canal block is commonly used as part of the multimodal analgesia following TKA. Despite the promise of prolonged pain relief, catheter-based ACB's for TKA patients has not translated into shorter length of stay or

Table 2 Skin-adductor canal distance measurements and relative changes from neutral position

\begin{tabular}{lll}
\hline Leg position & Skin-AC distance $(\mathrm{cm})$, mean $(\mathrm{SD})$ & Relative change in skin-AC distance $v s$ neutral $(\mathrm{cm})$ mean, $[95 \% \mathrm{CI}]$ \\
\hline Neutral & $5.1(0.8)$ & NA \\
Males & $5.0(0.8)$ & \\
Females & $5.2(0.8)$ & $1.0[0.8-1.2]$ \\
Manual displacement & $6.1(0.8)$ & $1.0[0.8-1.3]$ \\
Males & $6.1(0.6)$ & $1.0[0.2-1.3]$ \\
Females & $6.2(0.9)$ & $0.3[0.2-0.4]$ \\
External rotation & $5.4(0.8)$ & $0.2[0.1-0.4]$ \\
Males & $5.2(0.6)$ & $0.4[0.2-0.6]$ \\
Females & $5.6(0.9)$ & $0.4[0.3-0.6]$ \\
Straight leg raise to $30^{\circ}$ & $5.5(0.7)$ & $0.4[0.2-0.5]$ \\
Males & $5.4(0.6)$ & $0.5[0.2-0.7]$ \\
Females & $5.7(0.9)$ & $0.6[0.5-0.8]$ \\
Flexion to $90^{\circ}$ & $5.7(0.9)$ & $0.5[0.3-0.7]$ \\
Males & $5.5(0.6)$ & $0.8[0.6-1.1]$ \\
Females & $6.0(1.0)$ & $<0.001$ \\
\hline
\end{tabular}

$\mathrm{AC}=$ adductor canal $; \mathrm{NA}=$ not applicable $\mathrm{SD}=$ standard deviation $; \mathrm{CI}=$ confidence interval

( $n=40 ; 23$ males, 17 females) 
Table 3 Correlation of skin-adductor canal distance changes with anthropomorphic measurements

\begin{tabular}{llll}
\hline Leg position & Distance change $v s$ height $\left(\mathrm{R}^{2}\right)$ & Distance change $v s$ BMI $\left(\mathrm{R}^{2}\right)$ & Distance change $v s$ leg circumference $\left(\mathrm{R}^{2}\right)$ \\
\hline Manual displacement $v s$ neutral & 0.048 & 0.049 & 0.072 \\
External rotation $v s$ neutral & 0.063 & 0.005 & 0.012 \\
Straight leg raise $v s$ neutral & 0.003 & 0.052 & 0.048 \\
Flexion to $90^{\circ} v s$ neutral & 0.023 & 0.059 & 0.050 \\
\hline
\end{tabular}

BMI = body mass index, $n=40$.

improved functional recovery. ${ }^{13}$ The high failure rate and technical challenges with catheters have influenced us to opt for the single-shot ACB instead. As with other types of block that involve catheter insertion for drug administration, the main reasons for block failure are technical (e.g., pump failure, catheter disconnection), incorrect insertion of the catheter, and catheter tip migration. ${ }^{14}$ In this study, we show that leg movement can change the SAC distance. We speculate that with the catheter fixed to the skin, repeated movements of the leg with resulting changes in SAC distance could change the location of the catheter tip.

Height, BMI, and leg circumference did not correlate with SAC distance changes. In addition, SAC distance changes were similar in males and females. Although our sample was relatively small $(n=40)$, it represented a typical spectrum of anthropometry for patients undergoing TKA. Thus, our data suggest that patients at risk for exaggerated SAC distance changes cannot be predicted based on their physical characteristics or sex.

We acknowledge the following limitations of our study. The leg movements were passive in nature, and the effect of active muscle contraction on SAC distance change is unknown. Moreover, the standardized leg positions we assessed are only an approximation of those encountered during the postoperative course. We recognize that within each individual, the adductor canal runs a linear distance in the cranio-caudal direction, thus providing multiple possible target points for imaging and needle/catheter insertion. Measuring the SAC distance at the different points affects the absolute magnitude, but we do not believe that this influenced the relative SAC distance changes we observed because the same anchor points were used for measurements at baseline and following leg movement. Finally, the investigator performing the ultrasound measurements was not blinded to leg position. Practically speaking, such blinding would have been difficult to achieve even with an elaborate system of draping to obscure the leg's position.

Although it is plausible to suggest that leg movementassociated SAC distance changes cause catheter migration, this was not assessed in our study. Knowing how far to thread an ACB catheter is clinically relevant given that the SAC distance fluctuates with leg position. As the distal end of the catheter is fixed to the skin, one might expect that a shallow catheter insertion would increase dislodgement risk, while deep insertions may block the femoral nerve or exit the AC.

The present findings show changes in SAC distance at various leg positions. Real-time imaging of catheter tip migration associated with leg movement is required to help determine the optimal depth to thread the ACB catheter. We postulate that this will improve postoperative pain management in TKA patients.

Author contributions Steven Lee, Raymond Tang, Himat Vaghadia, and Jason Wilson contributed to study conception and design; analysis and interpretation of data; and drafting the article. Andrew Sawka contributed to study conception and design, and interpretation of data. Marcus Tholin contributed to study design; acquisition, analysis, and interpretation of data; and drafting the article.

Conflicts of interest Dr. Raymond Tang is a consultant for Clarius Medical Health, which does not conflict with this study.

Funding statement The project was funded internally by the Anesthesia Department at Vancouver General Hospital.

Editorial responsibility This submission was handled by Dr. Steven Backman, Associate Editor, Canadian Journal of Anesthesia.

\section{References}

1. Losina E, Thornhill TS, Rome BN, Wright J, Katz JN. The dramatic increase in total knee replacement utilization rates in the United States cannot be fully explained by growth in population size and obesity epidemic. J Bone Joint Surg Am 2012; 94: 201-7.

2. Lamplot JD, Wagner ER, Manning DW. Multimodal pain management in total knee arthroplasty: a prospective randomized controlled trial. J Arthroplasty 2014; 29: 329-34.

3. Kim DH, Lin Y, Goytizolo EA, et al. Adductor canal block versus femoral nerve block for total knee arthroplasty: a prospective randomized, controlled trial. Anesthesiology 2014; 120: 540-50.

4. Mariano ER, Perlas A. Adductor canal block for total knee arthroplasty: the perfect recipe or just one ingredient? Anesthesiology 2014; 120: 530-2. 
5. Jenstrup MT, Jaeger P, Lund J, et al. Effects of adductor canal blockade on pain and ambulation after total knee arthroplasty: a randomised study. Acta Anaesthesiol Scand 2012; 56: 357-64.

6. Hanson NA, Allen CJ, Hostetter LS, et al. Continuous ultrasoundguided adductor canal block for total knee arthroplasty: a randomized, double-blind trial. Anesth Analg 2014; 118: 1370-7.

7. Ahsan ZS, Carvalho B, Yao J. Incidence of failure of continuous peripheral nerve catheters for postoperative analgesia in upper extremity surgery. J Hand Surg Am 2014; 39: 324-9.

8. Marhofer D, Marhofer P, Triffterer L, Leonhardt M, Weber M, Zeitlinger $M$. Dislocation rates of perineural catheters: a volunteer study. Br J Anaesth 2013; 111: 800-6.

9. Salinas $F V$. Location, location, location: continuous peripheral nerve blocks and stimulating catheters. Reg Anesth Pain Med 2003; 28: 79-82.

10. Lee $S$, Rooban N, Vaghadia H, Sawka AN, Tang R. A randomized non-inferiority trial of adductor canal block for analgesia after total knee arthroplasty: single injection versus catheter technique. J Arthroplasty 2018; 33: 1045-51.

11. Turner JD, Dobson SW, Henshaw DS, et al. Single-injection adductor canal block with multiple adjuvants provides equivalent analgesia when compared with continuous adductor canal blockade for primary total knee arthroplasty: a double-blinded, randomized, controlled, equivalency trial. J Arthroplasty 2018; 33(3160-6): e1.

12. Wong WY, Bjorn S, Strid JM, Borglum J, Bendtsen TF. Defining the location of the adductor canal using ultrasound. Reg Anesth Pain Med 2017; 42: 241-5.

13. Salinas $F V$, Liu SS, Mulroy MF. The effect of single-injection femoral nerve block versus continuous femoral nerve block after total knee arthroplasty on hospital length of stay and long-term functional recovery within an established clinical pathway. Anesth Analg 2006; 102: 1234-9.

14. Jeng CL, Torrillo TM, Rosenblatt MA. Complications of peripheral nerve blocks. Br J Anaesth 2010; 105(Suppl 1): i97107.

Publisher's Note Springer Nature remains neutral with regard to jurisdictional claims in published maps and institutional affiliations. 